\title{
Lasers in Paediatric Dentistry, a Boon or a Bane: A Systemic
}

\section{Review}

\author{
Nilotpol K*, Sunil Kumar Y1, Manisha U1, Jyoti S1, Swarga Jyoti D² \\ and Manjula $\mathrm{D}^{3}$ \\ ${ }^{1}$ Department of Pedodontics and Preventive Dentistry, UCMS College of Dental \\ Surgery, Nepal \\ ${ }^{2}$ Department of Periodontology, Regional Dental College, India \\ ${ }^{3}$ Department of Prosthodontics, Regional Dental College, India
}

\section{Review Article}

Volume 4 Issue 1

Received Date: January 08, 2019

Published Date: February 04, 2019

DOI: $10.23880 /$ oajds-16000217

*Corresponding author: Nilotpol Kashyap, Department of Pedodontics and Preventive Dentistry, UCMS College of Dental, Bhairahawa, Nepal, Tel: 9811596307; Email: nilkash9365@gmail.com

\section{Abstract}

The American Academy of Pediatric dentistry (AAPD) recognised the judicious use of lasers as a beneficial instrument in providing dental restorative and soft tissue procedures for infants, children, and adolescence including those with special health care needs, through the development of this policy by the Council on Clinical Affairs in 2013. Lasers have been used in dental operators since 1987 and since then laser technology has advanced significantly. Lasers in paediatric dentistry is a boon since it causes less pain, has an analgesic effect on hard tissue, is vibration less, thus making the child patient comfortable and anxiety less.

Keywords: Lasers; Paediatric dentistry; Caries; Enamel

Abbreviations: AAPD: American Academy of Pediatric Dentistry.

\section{Introduction}

Lasers stands for Light Amplifiction by Stimulated Emission of Radiation (Figure 1). One of the first laser that was used by dental operators was a neodyniumytrium-alluminium-garnet (Nd:YAG) laser which was developed in 1987 [1]. The American Academy of Pediatric dentistry (AAPD) recognised the judicious use of lasers as a beneficial instrument in providing dental restorative and soft tissue procedures for infants, children, and adolescence including those with special health care needs, through the development of this policy by the Council on Clinical Affairs in 2013 [2]. 


\section{Open Access Journal of Dental Sciences}

\section{Classification of Lasers}

Based on active material: Gas lasers, Solid lasers, Liquid lasers [3]

Based on wavelength: Invisible ionising radiation, Visible, Invisible thermal radiation [4]

Based on their operating mode: Continuous, Pulsed [5]

Based on their power supply: Low power lasers, Mid power lasers

Based on delivery system: Flexible hollow waveguide or tubes, Articulated arms, Fiber optic

Based on clinical use: For diagnosis e.g. laser Doppler flowmetry, For non-surgical treatment e.g. laser activation of bleaching agent, laser activation of light curing materials, For surgical treatment, Soft tissue, Hard tissue, Combined

\section{Benefits of Lasers in Paediatric Dentistry}

There are many benefits of using lasers in paediatric dentistry over other methods like surgical blades, electrosurgery etc.

Some of the benefits are:

a) Lasers have selective and precise interaction with diseased tissues [3].

b) There is less necrosis in adjacent tissues with lasers as opposed to electrosurgery [4].

c) Haemostasis can be achieved without the need of sutures in most cases [5].

d) Post wound healing is faster with less discomfort, hence there is reduced need for analgesics [6].

e) Less or no anaesthesia is required for surgical procedures in soft tissues when lasers are used [7].

f) Reduced operator chair time [5].

g) Post-operative prescription of antibiotics is less because lasers have decontaminating and bactericidal properties [5].

h) Pain from apthous and herpetic ulcers can be relieved by lasers without pharmacological interventions [8].

i) Caries can be removed effectively by lasers with minimal involvement of surrounding tooth structures because caries affected tissues has higher water content than healthy tissues [4].

j) There is no noise and vibrations with the use of lasers [9].

k) The non-contact of lasers with hard tissue eliminates the vibration of a conventional high speed hand piece making tooth preparation to be comfortable and anxiety free for children [9].

l) Erbium and Nd: YAG lasers seems to have an analgesic effect on hard tissue thus eliminating the need for local anesthesia [10].

\section{Disadvantages of Lasers in Paediatric Dentistry}

a) The dentist might need more than one lasers since different wavelengths are required for various soft and hard tissue procedures.

b) Lasers are expensive [6].

c) Most instruments are both sight cutting and end cutting.

d) Lasers required high level of education and training.

e) Lasers may require modification of clinical techniques along with additional preparation with high speed hand piece to finish tooth preparation [3].

\section{Laser Basics}

Lasers are classified according to the active medium that is used to create the laser energy. An active medium is stimulated within a laser to produce photon of energy that is delivered in a beam of unique wavelength that is measured in nano meter [1]. The determining factor of the level to which the laser energy penetrates the intended tissue depends on the wavelength of the laser. The presence of chromophore or the laser absorbing element determines the intended target tissue's affinity for a specific wavelength of laser energy [11]. Oral hard and soft tissues have a distinct affinity for absorbing laser energy of a specific wavelength and this is why a dentist has to select a specific laser depending on the target tissue that he wants to treat [12].

Photothermal is the primary effect of lasers within the targeted tissue and when the temperature of the targeted tissue containing water is raised above 100 degrees the vaporisation of the water occurs resulting in soft tissue ablation. On the other hand hard tissue which are composed of hydroxyapatite crystals and minerals are not ablated at this temperature, but the water component is vaporised and the resulting steam expands and disperses the encompassing material into small particles [13].

\section{Application of Lasers in Paediatric Dentistry}

These can be divided into soft tissue and hard tissue procedures.
a) Soft tissue applications
b) Paediatric endodontics
c) Treatment of mucocele
d) Dentigerous cyst
e) Frenectomy
f) Ankyloglossia
g) Herpes labialis lesions
h) Apthous ulcers
i) Exposure of teeth to help in the eruption of teeth
j) Gingival remodelling and gingivectomy 
k) Leukoplakia

\section{Hard Tissue Applications}

a) Caries detection by lasers

b) Caries removal

c) Prevention of enamel and dental caries

d) Cavity preparation

e) Pit and fissure sealants

f) Curing of light activated composites

g) Laser paediatric crowns

h) Laser fusion of vertical root fracture

i) Removal of old restorative materials

j) Orthodontic tooth movement

k) Dental traumatology

l) Laser analgesia

m) Bleaching of vital and non-vital teeth

\section{Soft Tissue Applications}

Lasers in Pediatric Endodontics

Diagnosis: Diagnosis of vital and non-vital dental pulp can be done by laser doppler flowmetry. If the normal pulp is stimulated by pulse laser at $2 \mathrm{w}$ and 20 pulses per second at a distance of $10 \mathrm{~mm}$ from the tooth surface, the patient will feel pain in 20-30 seconds. In the case of acute pulpits pain is felt immediately and for more than 30 seconds after the stoppage of laser stimulation.

Indirect pulp capping: In case of indirect pulp capping analgesia is not required with lasers due to less heat generation in the pulp chamber. The pulp capping is superior and is attained upto the depth of 310 micro meter [14].

Direct pulp capping: When laser is used for DPC the bleeding can be controlled and sterilisation is induced. Erbium lasers at $1 \mathrm{~W}, 20 \mathrm{~Hz}$ with $20 \%$ air and $15 \%$ water is generally used.

Pulopotomy: Pulpotomy is one of the most successful treatment in paediatric dentistry with the use of laser. Amputation of the coronal pulp can be attained at a satisfactory level. Control of hemorrhage is done by putting the tip of laser hand piece 3-4 m away with a power setting of $30-40 \mathrm{~mJ}$ without the use of water spray and air is used at $30 \%$ [15].

Access cavity and canal preparation: Generally Er, Cr: YSGG lasers are used for access cavity preparation and root enlargement and pulsed Nd:YAG laser with $2 \mathrm{~W}$ at 20 pps for 1 second is recommended to strerilise the infected root canals. Lasers are contraindicated in case of curved and narrow root canals.

Treatment of mucocele: When laser is used to excised mucocele under local anesthesia using 300 micro meter diameter tip at $1.3 \mathrm{~W}$, healing is uneventful and there is no recurrence [16].
Dentigerous cyst: Lasers can be used to vaporise bony cavity in case of dentigerous cyst which are common in unerupted tooth in mixed and permanent dentition. Lasers can also be used to curette the lining of the cystic cavity [17].

Frenectomy: In children having midline diastema due to high frenum attachment, Er:YAG lasers can be used at a setting of $30 \mathrm{~Hz}$ and $50 \mathrm{~mJ}$ and the laser energy is directed at the insertion of the frenum and area between the two central incisors [18].

Ankyloglossia: Ankyloglossia can lead to tongue tie and makes speaking challenging. Er: YAG at a setting of $30 \mathrm{~Hz}$, $50 \mathrm{~mJ}$ with no water can be used to cut the frenum. A suture is generally placed at the junction of the frenum and of the cut to prevent reattachment [19].

Herpes labialis lesions: Nd:YAG laser can be used in the free running pulse in an area of defocused non-contact mode for the treatment of herpes labialise lesions. The laser energy arrests the progression of lesions, stops the viral activity and also prevent the recurrence of the lesions [20].

Apthous ulcers: Apthous ulcers are painful lesions which causes problems during eating and speaking. These lesions can be treated by laser energy in a focused mode which is directed into the surface of these lesions to remove the exposed nerve endings [14].

Exposure of tooth to help in tooth eruption: In case of teeth which have not erupted, lasers can be used to expose the tooth and allow for its eruption without any damage to tooth enamel. For location and exposure of the tooth which are unerupted, lasers that are not absorbed into the enamel are ideal. Er: YAG at a setting of $30 \mathrm{~Hz}$, $45 \mathrm{~mJ}$ in contact and non-contact mode is generally used [21].

Gingival remodelling and gingivectomy: Erbium laser at a setting of $55-80 \mathrm{~mJ}$ and frequency of $20-30 \mathrm{~Hz}$ without water spray is generally used for gingival remodelling and gingivectomy [22].

Leukoplakia: Ablative Er: YAG laser with non-contact digitally controlled hand piece is used for the removal of leukoplakia. The hand piece is held at a distance of $15 \mathrm{~mm}$ form the lesion surface with the water spray set at $10 \mathrm{ml}$ per minute. The laser is set at a pulse energy of $120 \mathrm{~mJ}$ at QSP mode and a frequency of $20 \mathrm{~Hz}$ [23].

\section{Hard Tissue Applications}

Caries detection by lasers: Laser fluorescence is used to measure the fluorescence of the tooth that is induced after light irradiation to discriminate between carious and sound enamel. Laser fluorescence is used for caries detection on occlusal surfaces. It is a chair side, battery powered quantitative diode laser fluorescence device that emits light at $655 \mathrm{~nm}$ wavelength from a fibre optic bundle 
onto the occlusal surface of the tooth. A second fibre optic bundle receives the reflected fluorescent light beam. Changes caused by demineralisation are assigned a numeric value which is displayed on a monitor. The system is calibrated to a provided standard and to reference enamel. Disadvantages are it may give false positive reading, it may not reach the deeper dentinal layers thus cannot distinguish between superficial and dentinal decay and it is not efficient at detecting caries in non cavitated teeth [24].

Caries removal: Hibst and Keller in 1980 were the first to used Er: YAG lasers to remove dental caries. laser removal of dental caries falls into the category of minimal invasive dentistry. When lasers are used they ablate small area of infected layer and thus conserve the tooth structure. Lasers also sterilize the affected layer while retaining its remineralising potential. Layers also vaporise the smear layer providing a better retention of composite resin to the dentin.

Prevention of enamel and dental caries: Lasers have been used for the prevention of dental caries since 1960's. The lasers that were used were ruby, Nd: YAG, CO2 and argon lasers.

When enamel is treated with lasers they show the following properties:

a) Increased acid resistance- Lased enamel shows increased acid resistance due to ultra-structural alterations, as a result of melting and resolidifying.

b) Organic blocking theory- The partial denaturation of organic matrix blocks the diffusion pathway in enamel which results in less enamel demineralisation.

c) Combination of reduced enamel permeability and enamel solubility- A decrease in the size of the apatite crystals due to loss of water and carbon dioxide makes the hydroxyapatite crystals more compact after laser irradiation resulting in increased enamel resistance to acids.

d) Lasers can alter the chemical composition and morphology of the enamel by photo-thermal mechanism resulting in increased $\mathrm{Ca} / \mathrm{P}$ ratio, decreased amount of carbonate and protein and the formation of tricalcium phosphate and tetra calcium phosphate.

Cavity preparation: Ablation is the mechanism through which lasers are used for cavity preparation. Dental hard tissue is removed by thermal and mechanical effect during laser irradiation. A focused mode and a defocused mode is used for fast cutting and slow cutting respectively. In case of deep cutting the tip of the hand piece is moved up and down in a pumping action. Different tooth structures can be identified by hearing the sound of the ablation. For cutting enamel during cavity preparation is $6 \mathrm{~W}$ at $32 \%$ water level and maximum air pressure level is used. For cutting dentin power is reduced to $3 \mathrm{~W}$ at $20 \%$ water level and 70\% air level [25]. Advantages of laser cavity preparation

a) The cavity that is prepared by laser is irregular in shape and is ideal for placement of composite and GIC.

b) Structure and strength of the tooth is maintained.

c) The step of acid etching during composite restoration can be avoided.

Pit and fissure sealants: John in 1997 found a interlacing pattern of thin partitions and small knob like expansions in laser etched enamel. These alterations provides space for the retention of pit and fissure sealants thus preventing micro leakage, which can produce caries under the pit and fissure sealants [26].

Curing of light activated composites: Laser irradiated dentin maintains favourable diffusion of monomer through the collegen network, this helps in the retention of composite resins. Lasers also require less time to achieve polymerisation of composites. Lasers also reduce chair time and is specially helpful with restless children. Lasers also requires less exposure time [27].

Laser paediatric crowns: The technique of laser paediatric crown was first postulated by Jacboson in 2003 [28].

Tooth preparation: This technique of crown preparation eliminates the need of local anaesthesia. The surface layer of enamel is cut with a laser at a setting of $5.5 \mathrm{~W}$ with $65 \%$ air and 55\% water levels. The preparation of crown follows the same specifications as the conventional method. The tooth surface is left roughened so that it bonds with the luting cement. Buccal, lingual, mesial and distal wall do not require occlusal taper. The bonding of the crown is improved by placing undercuts on the enamel surface.

Laser fusion of vertical root fracture: Dederich in 1999 observed good filling of the bone defect in vertical root fracture by using the laser at $15 \mathrm{~W}$ for $0.2 \mathrm{sec}$ with spot diameter of $1.0 \mathrm{~mm}$ in 15 single exposures with an average of 5 sec lapse time between exposure [29].

Removal of old restorative materials: Removal of Amalgam filling are contraindicated with lasers because laser ablation causes release of mercury vapour. Removal of composite and GIC fillings with Er:YAG laser was first done by Hibst and Keller [30].

Orthodontic tooth movement: The retraction of maxillary canine into the first premolar extraction spaces along with fixed edge wise appliance was done by low level laser therapy (LLLT) at 8J/cm2 energy density at $100 \mathrm{~mW}$ [31].

Dental traumatology: For uncomplicated and complicate d fractures of the crown Er, Er: YAG, diode, CO2 and Cr: YAG lasers are most frequently used. 
Laser analgesia: Lasers have an analgesic effect on the nerves of the oral cavity by decreasing the firing frequency of nociceptors with a threshold effect by maximum suppression. The duration of analgesia is 15 minutes and is helpful in patients who have a phobia of needles [14].

Bleaching of vital and non-vital teeth: Power bleaching can be achieved by the use of lasers which is the most efficient energy source while avoiding its adverse effects [32].

\section{Laser safety:}

a) A mixture of gas and debris which is known as the laser plume is produced during the use of lasers which is why the dentist and the auxiliaries should adhere to infection control protocol and use high speed suction as the dental plume may contain infective tissue particles.

b) Palliative pharmacological therapies should be used on patients with viral lesions [15].

c) Laser beams which are scattered and reflected are hazardous to unprotected skin and eyes and that is why wavelength specific protective eyewear should e used by the dental team as well as the patient [3].

Hazards of lasers: Although the world has seen a growth in the use of lasers in the dental operatory, there are still many hazards associated with lasers [33].

They are as follows:
a) Ocular hazard
b) Tissue damage
c) Respiratory hazard
d) Fire and explosion
e) Electrical shock
f) Combustion hazard
g) Equipment hazard

\section{Conclusion}

Lasers have been used in dental operators since 1987 and since then laser technology has advanced significantly. Lasers in paediatric dentistry is a boon since it causes less pain, has an analgesic effect on hard tissue, is vibration less, thus making the child patient comfortable and anxiety less.

\section{References}

1. Shanthi M (2015) Laser Prescience in Pediatric Dentistry. International Journal of Scientific Study 3(2): 197-203.

2. (2007) AAPD policy on the use of lasers for pediatric dental patients pp: 95-97.
3. Coluzzi DJ (2005) Lasers in dentistry. Compend Contin Educ Dent 26(6): 429-435.

4. Coluzzi DJ (2008) Fundamentals of lasers in dentistry: Basic science, tissue interaction and intrumentation. J Laser Dent 16(spec issue): 4-10.

5. Boj JR, Poirer C, Hernandez M, Espassa E, Espanya A (2009) Review: Laser soft tissue treatments for paediatric dental patients. Eur J Pediatr Dent 12(2): 100-105.

6. Olivi G, Genovese MD, Caprioglio C (2009) Evidence based dentistry on laser paediatric dentistry: Review and outlook. Eur J Pediatr Dent 10(1): 29-40.

7. Convissar RA, Goldstein EE (2003) An overview of lasers in dentistry. Gen dent 51(5): 436-440.

8. Green J, Weiss A, Stern A (2011) Lasers and radio frequency devices in dentistry. Dent Clin North Am 55(3): 585-597.

9. Tanboga I, Eren F, Altsnok B, Peker S, Ertugral F (2011) The effect of low level laser therapy on pain during dental tooth cavity preparation in children. Eur Arch Paediatr Dent 12(2): 93-95.

10. Olivi G, Genovese MD (2011) Laser restorative dentistry in children and adolescents. Eur Arch Paediatr Dent 12(2): 68-78.

11. Fasbinder DJ (2008) Dental laser technology. Compend Contin Educ Dent 29(8): 452-459.

12. Myers TD, Myers ED, Stone RM (1989) First soft tissue study utilizing a pulsed Nd: YAG dental laser. Northwest Dent 68(2): 14-17.

13. Martens LC (2011) Laser physics and a review of laser application in dentistry for children. Eur Arch Paediatr Dent 12(2): 61-67.

14. Pillai R, Sujathan UN, Jacob AS, Abdulsalim A, Sainudeen S (2014) Hard tissue lasers: An insight. J Interdiscip Dent 4(3): 110-117.

15. Toomarian L, Fekrazad R, Sharifi D, Baghaei M, Rahimi H, et al. (2008) Histopathological evaluation of pulpotomy with Er, Cr: YSGG laser vs formocresol. Lasers Med Sci 23(4): 443-450.

16. Pandey R, Pathakota KR, Koppolu P, Bolla V (2013) Treatment of mucocele with diode laser. J Dent Lasers $7(1): 43-46$. 


\section{Open Access Journal of Dental Sciences}

17. Boj JR, Poirier C, Hernandez M, Espasa E (2007) Laser-assisted treatment of a dentigerous cyst: Case report. Pediatr Dent 29(6): 521-524.

18. Pie Sanchez J, Espana-Tost AJ, Arnafat-Dominquez J, Gay-Escoda C (2012) Comparative study of upper lip frenectomy with the $\mathrm{CO} 2$ laser versus the $\mathrm{Er}, \mathrm{Cr}$ : YAG laser. Med Oral Patol Oral Cir Bucal Mar 17(2): 228232.

19. Kotlow L (2011) Diagnosis and treatment of ankyloglossia and tied maxillary fraenum in infants using Er: YAG and 1064 diode lasers. Eur Arch Paediatr Dent 12(2): 106-112.

20. Rallis TM (2000) Low-intensity laser therapy for recurrent herpes labialis. J Invest Dermatol 115(1): 131-132.

21. Boj JR, Poirier C, Espasa E, Hernandez M, Jacobson B (2006) Eruption cyst treated with a laser powered hydrokinetic system. J Clin Pediatr Dent 30(3): 199202.

22. Guelmann M, Britto LR, Katz J (2003) Cyclosporininduced gingival overgrowth in a child treated with CO2 laser surgery: A case report. J Clin Pediatr Dent 27(2): 123-126.

23. Ishii J, Fujita K, Komori $T$ (2003) Laser surgery as a treatment for oral leukoplakia. Oral Oncol 39(8): 759769.

24. (2017) AADC Position statement: laser fluorescence in caries diagnosis.

25. Freitas PM, Navarro RS, Barros JA, de Paula Eduardo C (2007) The use of Er: YAG laser for cavity preparation: an SEM evaluation. Microsc Res Tech 70(9): 803-808.
26. Brugnera Jr A, Rosso N, Duarte D, Pinto AC, Genovese W (1997) The use of carbon dioxide laser in pit and fissure caries prevention: Clinical evaluation. J Clin Laser Med Surg 15(2): 79-82.

27. Schein MT, Bocangel JS, Nogueira GE, Schein PA (2003) SEM evaluation of the interaction pattern between dentin and resin after cavity preparation using ER: YAG laser. J Dent 31(2): 127-135.

28. Jacboson B, Berger J, Kravitz R, Patel P (2003) Laser pediatric crowns performed without anesthesia: A contemporary technique. J Clin Pediatr Dent 28(1): 11-12.

29. Dederich DN (1999) CO2 laser fusion of a vertical root fracture. J Am Dent Assoc 130(8): 1195-1199.

30. Hibst R, Keller U (1991) Removal of dental filling materials by Er: YAG laser radiation. SPIE 1424: 120126.

31. Limpanichkul W, Godfrey K, Srisuk N, Rattanayatikul C (2006) Effects of low- level laser therapy on the rate of orthodontic tooth movement. Orthod Craniofac Res 9(1): 38-43.

32. Buchalla W, Attin T (2007) External bleaching therapy with activation by heat, light or laser - A systematic review. Dent Mater 23(5): 586-596.

33. Kumar B, Kashyap N, Avinash A, Munot H, Pawar P, et al. (2017) The hazardous effects of safety measures of lasers in dentistry: A review. Int J Cont Dent Med Rev pp: $1-5$. 